\title{
Herminio en Compostela. Pedagoxía e cordialidade
}

\author{
Miguel Anxo SANTOS REGO \\ Universidade de Santiago de Compostela
}

Coido que foi o derradeiro libro de Herminio Barreiro, compañeiro e amigo na USC, o que levou por título "Recordar Doe". Poucas portadas teño visto tan directas aos miolos da conciencia, ao núcleo dun ser atravesado pola memoria dun tempo de silencio. E por iso, cando chegou a hora de falar non era -como escribiu Manuel Rivas (El País, 30/05/2008) - para andarse con andrómenas.

O relato (auto)biográfico é sempre complexo, e mesmo incompleto xa que nos vemos obrigados a desbrozar aspectos e dimensións aparentemente destacados para unha lectura racionalmente instalada en parámetros de pública avaliación, pero que case sempre carecen das claves intra-históricas que permitirían unha comprensión máis holística ou totalizadora do que ten acontecido ao noso arredor. Velaí a vizosa consulta desa obra 'intimista' escrita no solpor dunha vida que resume, primeiro a traxedia e despois a esperanza do país, a través das circunstancias que marcan o devir socio-familiar da persoa que, coa súa pegada intelectual, nos move a lembralo, agradecendo no meu caso a magnífica oportunidade de facelo ao carón do estudo que me abriu as portas a unha traxectoria universitaria que xa ten superado as tres décadas de implicación na docencia, na investigación, e na xestión ao servizo desta gran casa do saber na que teño a honra de traballar.

Sen parangón posible cos motivos que latexan detrás do título dado ao volume de Xerais, a dor de quen asina esta nota tal vez sexa máis levadeira pero sen mágoa de sentido e fonda sensibilidade por amosar a valía moral dunha mensaxe que a andaina inaugural de pedagogas e pedagogos desta Universidade soubemos captar como grandes afortunados dunha docencia (de 'Historia da Educación', basicamente) que Herminio revalorizou coa súa figura de home ao que resultaba doado fusionar as dúas competencias nas que fermenta o ensino de calidade: un saber cognitivo (dominio disciplinar) e un saber afectivo (dominio relacional). Se o primeiro se lle supón ao profesorado universitario por simple deriva formal de especializada postulación académica, o segundo é caracterialmente disposicional, unha sorte de capital social, de intelixencia emocional en constante fluxo que seduce no intre do contacto e aínda dilata os seus atraentes efectos na escoita da palabra cordial que preludia confianza para acudir na procura de calquera esclarecemento ou consello sobre como apurar os vieiros da aprendizaxe.

Tales son as bondades dunha epifanía pedagóxica que poucos son quen de xuntar no seu 'ser e estar', dun xeito tan ecoloxicamente humano, como o compañeiro que se foi 
con tanto adianto e sen darnos tempo a poder agasallalo co agarimo que simboliza, nas ocasións de xúbilo, un gran libro homenaxe.

Se o Profesor Barreiro Rodríguez chegou a merecer a categoría de mestre por cantos o ouviron e trataron non foi precisamente polo seu anceio ou lexítima ambición credencialista nunha carreira de atrancos que o sistema deturpou con grave perxuízo dos climas de convivencia e colaboración nas áreas e departamentos, senón polo seu desprendemento persoal diante do feixe de cometidos que solicitaban participación e compromiso coas decisións colexiadas. Haberá outras razóns para que non decaera a miña consideración cara el co tránsito desde a condición de alumno á de colega no seo da 'Alma Mater', pero esa natural tendencia ao diálogo sosegado, á ponderación de criterio, en conxunturas de 'crispación situada', axudou sen dúbida algunha.

A débeda non é cativa e a memoria serve para axustala segundo as coordenadas dunha época (morte de Franco, inicio dos estudos de Pedagoxía en Galicia, transición desde unha ditadura a unha democracia) necesitada de alicerces para a reconstrución efectiva das liberdades e, xa que logo, dun sistema educativo ateigado entón de miseria cívica e dun secular atraso científico. Non fun o único, pero si dos primeiros en calibrar o alcance das vantaxes formativas que propiciaba a proximidade dun docente que era xermolo de innovación na análise do discurso pedagóxico e ariete de combinacións metodolóxicas con posibilidades de abrir máis vías ao coñecemento social, sobranceiro referente do coñecemento educativo, como adoitaba comentar.

Pertenzo á promoción dos que rematamos a carreira no Colexio de Fonseca (1978), emblemático edificio que frecuentei sendo estudante, e anos despois como Vicerreitor de Profesorado da USC, nomeadamente cando celebramos o quinto centenario da súa fundación. Alí recalou Herminio como profesor contratado para ensinar Historia da Educación a quen xa tiñamos superado o primeiro ciclo, e empezabamos a albiscar o remate da boa vida de estudante, mesmo un pouco antes do lustro por ser nós os afectados daquela estrambótica idea dun ministro no tardo-franquismo (Julio Rodríguez), empecinado en cambiar o calendario académico cando discorría o ano de 1974.

Era da terra, viña de Madrid e falaba un galego docemente fresco, que semellaba destilar ideais representacións xurdidas ou sementadas ao abeiro de vivencias mozas no Salnés. Co despertar da democracia, pactada daquela, moitos eran os temas, correntes e autores que aguilloaban a nosa curiosidade na materia, esporeada maxistralmente por Herminio para pór en valor ético ideas e accións educativas longo tempo marxinadas no elenco editorial do ramo ou simplemente silenciadas no currículo oficial. Era o caso, entre outros eixos programáticos, da Institución Libre de Ensinanza e da Política Educativa da Segunda República, asuntos que estaban no guión ou, se se prefire, na axenda da selecta pescuda histórica (como puxeron de relevo as ducias de artigos, libros e monografías saídas do prelo por entón e manufacturadas desde instancias científica e academicamente diversas).

Tamén eu fiquei enormemente interesado por ampliar os meus horizontes cognitivosociais nese caladoiro de influxos paradigmáticos e de vínculos expresivos dunha reci- 
procidade aliñada por ideais de progreso e xustiza. A converxencia de factores varios naqueles anos de magna ilusión colectiva, malia a treboada sufrida na viaxe a un país homologable no concerto das nacións 'civilizadas', precipitou unha vocación que o meu pai (mestre en escolas e pobos ciscados no mapa español e galego) xa inducira, non con palabras, senón con discretas invitacións ao repaso crítico dun legado extraordinario na pedagoxía, que discorría parello ao que se chamou a idade de prata da cultura en España.

Se quería ser algún día profesor universitario, e neste eido para sermos máis concretos (aspecto pouco confesado de quen medrou ouvindo falar moito e ben de educación), a ocasión chegaba coas circunstancias: o gosto polo estudo e un contexto de crecemento universitario que prometía oportunidades de incorporación a un claustro en cernes, dentro dunha Facultade -Filosofía e Ciencias da Educación- que en 1978 apenas contaba con profesorado estable (dicíanlles PNNs, isto é, Profesores Non Numerarios) e na que a gran maioría dos docentes estaban (pre)ocupados na realización das súas teses de doutoramento.

Só faltaban os mentores. E para a miña fortuna estaban preto, alentándome a dar os primeiros pasos por onde había que dalos, ou sexa, propondo un tema de investigación a validar como grao de licenciatura (tesiña), posible antesala dunha prezada bolsa de formación do profesorado universitario (FPU), e mesmo dunha praza de Axudante que dera folgos á carreira académica.

Foi a visión de Herminio e a súa xenerosidade a que deu pulo ás miñas ansias de saber pesquisador. $O$ seu ánimo axiña mudou en consello a prol dun achegamento introdutorio á obra de Lorenzo Luzuriaga, pedagogo de prístina raigame institucionista, impulsor, cando non arquitecto, de iniciativas da política educativa republicana, fundador da prestixiosa Revista de Pedagogía (1922) e autor dunha vigorosa nómina de libros, amén doutras contribucións imbuídas de acentos vangardistas, aparecidas en Madrid e Buenos Aires, cidade do seu exilio e morte en 1959. Dato moi significativo este pois os que fomos, alumnos do homenaxeado sabemos das veces que citaba (e da fruición con que o facía) algúns títulos co selo de Luzuriaga, a saber: Historia de la Educación y de la Pedagogía, Las Escuelas Nuevas Alemanas, Pedagogía Social y Política, La Escuela Unificada, La Escuela Única, ou o mesmo Diccionario de Pedagogía, verdadeiro precursor dunha xeira de fontes documentais para cultivo de persoas que investigaban, e soporte de persoas que opositaban.

Estas e outras obras estaban na lista dos libros cos que se acompañaba Herminio nas clases e seminarios, co degoiro de que chegáramos a entender o senso dinámico que as propulsaba no marco dunha estrutura social que en España parecía máis propia do medievo que da modernidade. Pero, aínda máis, tales referencias de autor serían unha pedra de toque considerable na súa vontade de mergullarse, alén do que eu lograra sistematizar, na investigación do papel xogado polo pedagogo manchego na renovación da educación en España, a súa espléndida tese de doutoramento trenzada unha vez que eu decidira -e transmitira - tomar un desvío no meu camiño ao futuro. 
A súa xentil dispoñibilidade foi tal que aceptou con absoluta naturalidade e bo humor o 'detalle' burocrático de non poder formar parte do tribunal que xulgou a tesiña ("Aproximación a la obra pedagógica de Lorenzo Luzuriaga"), e mesmo - paradoxalmente- de non ver o seu nome xunto ao dos colegas que, sendo doutores, cumprían as cláusulas da norma: Gonzalo Vázquez Gómez (Ponente), daquela pertencente ao extinto corpo de "Profesores Agregados de Universidad", e Carlos Rosales López (Director), cunha praza dotada interinamente, a quen tamén agradezo a súa exquisita prestancia e colaboración. Tratei, iso si, de clarexar as cousas no apartado de 'agradecementos' co que pechaba 0 prefacio do volume: “...pero, sobre todo, al Profesor Herminio Barreiro, sin cuyo inestimable y continuo aliento, orientación y consejo, no hubiera sido posible la realización de este modesto trabajo de investigación".

Así transcorreu unha parte decisiva dos meus anos mozos. Unha etapa de formación asistida por múltiples estímulos nunha cidade chea de vida cultural, daquela un calidoscopio excepcional onde enxergar esperanza no porvir. Que profesores como Herminio alimentaban acotío con suxestivas hipóteses de estudo.

Xa quixera eu que a recuperación e re-lectura da Memoria de Licenciatura, que custodio con toda ledicia e orgullo na miña biblioteca, tivera un motivo distinto ao de escribir, respondendo á amable invitación feita desde o Departamento, en lembranza de quen, por enriba de todo, e de todos, nos foi amosando maneiras de seguir vendo na universidade pública unha estrada de liberdade, igualdade e fraternidade. Con iso abonda para non esquecer o seu testemuño de cordialidade dentro e fóra das aulas, no Campus ou nas Rúas de Compostela, proxectando a potencia dunha virtude que tanto optimiza o diálogo e, conseguintemente, a aprendizaxe. 